\title{
Research on the business model innovation applicable to intelligent bucket in medical and chemical industry
}

\author{
Liu Feng ${ }^{1, \mathrm{a}}$, Chen Feifei ${ }^{2, \mathrm{~b}}$, Jiang Yichen ${ }^{3, \mathrm{c}}$, Chang Yichen ${ }^{4, \mathrm{~d}}$, Lan Mei ${ }^{5, \mathrm{e}}$, Chen Jia'ni ${ }^{6, \mathrm{f}}$, Jin Zhiqi ${ }^{7, \mathrm{~g}}$, Wang Ningbo ${ }^{8, \mathrm{~h}}$, Yang \\ $\mathrm{Jie}^{9, \mathrm{i}}$ \\ ${ }^{1}$ School of Computer Science and Technology, East China Normal University, Shanghai, China \\ ${ }^{2}$ Institute of Finance Management, Shanghai University of international Business and Economics, Shanghai, China \\ ${ }^{3}$ Institute of Finance Management, Shanghai University of international Business and Economics, Shanghai, China \\ ${ }^{4}$ Institute of Finance Management, Shanghai University of International Business and Economics, Shanghai, China \\ ${ }^{5}$ Institute of Finance Management, Shanghai University of international Business and Economics, Shanghai, China \\ ${ }^{6}$ Institute of international business and foreign languages Shanghai University of International Business and Economics, Shanghai, China \\ ${ }^{7}$ Institute of Internet of Things Engineering, Wuxi Taihu University, Wuxi, China \\ ${ }^{8}$ Institute of Internet of Things Engineering, Wuxi Taihu University, Wuxi, China \\ ${ }^{9}$ Institute of Electronic and Computer Engineering, Southeast University Chengxian College, Nanjing, China
}

\begin{abstract}
As an important category of urban waste, medical waste has the characteristics of polluting the environment, spreading diseases, and threatening health. It is directly related to the health of the people. The treatment of medical waste is an important part of epidemic prevention and control, and it is also a line of public health defense. This article proposes a business model that combines "C2M + multi-channel marketing" and "Internet of Things + medical" trash cans. Through market analysis, it analyzes the market situation of medical waste pretreatment link in China-medical trash can. Through the 4P marketing theory, a medical trash can be based on the Internet, which is designed mainly from the product perspective and the $\mathrm{C} 2 \mathrm{M}$ production model is adopted; from the channel perspective, the product is first tested and sold through multiple channels.

This article aims to implement the "Medical Waste Management Regulations" for the medical trash can industry and open the market to provide new ideas for reform and innovation.
\end{abstract}

\section{Introduction}

The medical trash can is an essential medical appliance in every hospital. It is mainly used for the cleaning and transportation of low-value medical consumables. According to speculation, the market size of the medical trash can is about 9.75 billion yuan. Although the traditional plastic medical trash cans are still in use today, the medical trash cans on the market have simple functions. In actual operation, various medical wastes may be mixed and discarded, resulting in the risk of virus infection or toxic gas transmission, medical waste transportation is inconvenient and medical waste bins have market pain points. With the advent of the smart era, the trash can is an indispensable daily necessity in human life, and smart trash cans are also becoming popular. They have been welcomed by consumers since their listing. Due to the large market demand and small investment, they have also received small and mediumsized investments and the favor of the audience. This article uses 4P marketing theory to design a new business model of medical trash cans, which aims to combine smart trash cans with medical trash cans to realize the intelligent of medical trash cans and improve the safety of medical trash cans. The Internet of Things technology connects the smart medical trash can into a network to realize centralized management and monitoring. Using the $\mathrm{C} 2 \mathrm{M}$ sales model, customers are directly connected to manufacture, and customized products are manufactured according to the classification of medical waste. Before sales, use resources to carry out initial pilot cooperation, and later adopt the "direct sales + dealer + e-commerce" method of sales, multi-channel 
sales, direct information to customers, and rapid market expansion.

\section{Literature review}

According to the current sales model, different scholars have different research. Hu Hanmin discussed the sales model of medical devices which based on the current development status of the medical device market, and on this basis discussed how to optimize the sales model of medical devices based on the existing $\operatorname{market}^{[i]}$. According to the research and development design, production, management, sales and service, Ao XiaoBo et al. actively applied the concepts of "made in China 2025 " and "Internet +", and gradually formed a set of F2C mode of enterprise manufacturing process, then realized the enterprise cash flow, information flow and

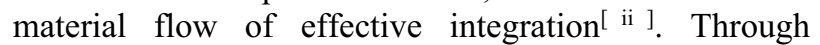
construction services to network platform, they has realized the integration of product and service, and created a huge value for the enterprise. Dong Xiaozhi aimed at some problems in the transition from direct selling model to "Internet + direct selling", and introduced C2M theory "Internet + direct selling" mode, to provide a direct sales model to the Internet is the new idea of transition, to effectively solve the contradiction between the high quality requirements of producer, low cost, high profit and low consumer prices ${ }^{[i i i]}$.

\section{Business Model Introduction/method}

\subsection{Market background}

Due to the lack of Market Research on the medical garbage can and the fact that the intelligent medical garbage can is basically not used, it is difficult to obtain the market scale of the medical garbage can directly. The function of medical garbage can is mainly used to clear and transport low-value medical consumables, so we can infer the market size of medical garbage cans from the market scale data of low-value medical consumables.

Taking the injection puncture consumables as an example, the market size is about 19.5 billion yuan, and the price of single syringe is about 1 yuan. Assuming that all the injection puncture consumables are syringes, the market scale of syringes is about 19.5 billion. If a sharp tool box can handle 10 syringes, 1.95 billion sharp tool boxes are needed, and the unit price of the sharp tool box is about 1.5 yuan, and the market scale is about 292500 yuan. The market scale of medical garbage can is estimated to be about 9.75 billion yuan, because the injection puncture accounts for $30 \%$ of the low value medical consumables ${ }^{[i v]}$.



Source: Wind beries Blue Bock

Figure 1 market segmentation of medical consumables

TABLE I low value medical consumables in China

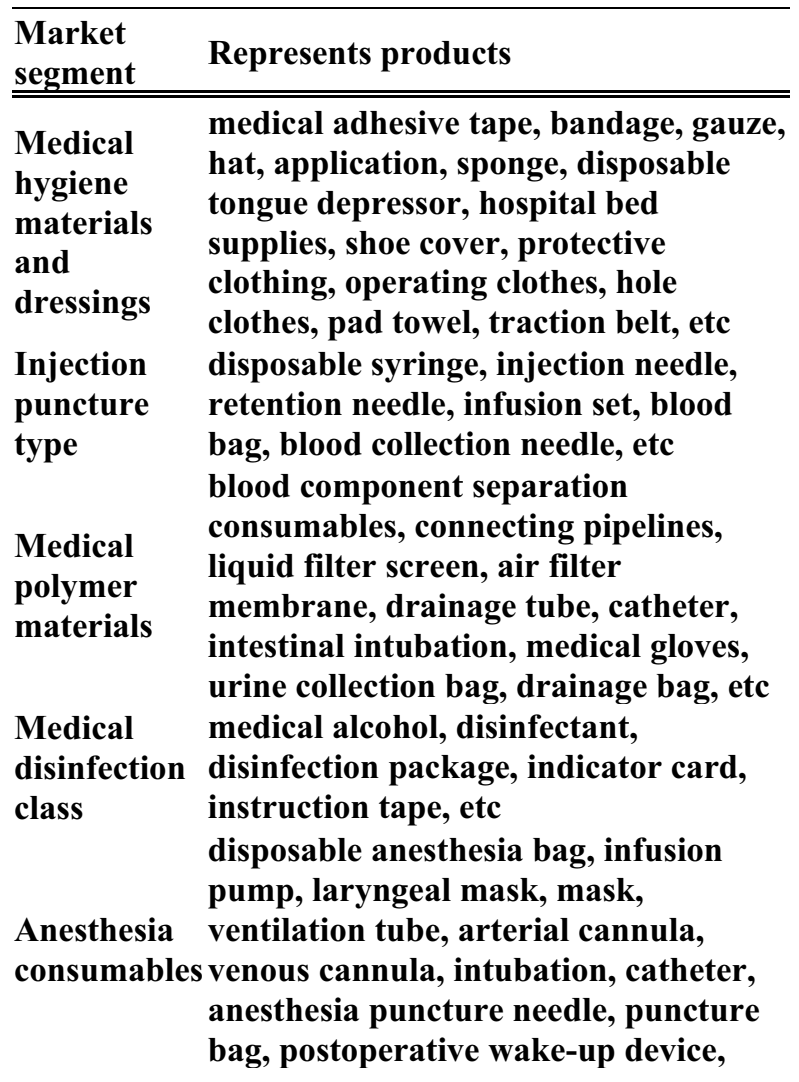


anesthetic gas filter, anesthetic gas purifier, sensor, detection electrode piece, etc

disposable hand tools, perfusion

devices, medical suture needles, sutures, absorbable sutures,

Operating

room

sterilization harness, electric knife, consumables electrocoagulation forceps, scalpel, surgical blade, medical skin preparation knife, medical glue, click, puncture device, suction head, etc B-ultrasound printer, couplant, conductive paste, ECG electrode, EEG drawing, urine analyzer printing Medical paper, sublimation printing paper, technical high-pressure syringe needle, highconsumables pressure syringe needle head, disposable photo connecting tube, medical X-ray film, medical CT (MR) film, laser film, etc

\subsection{Adapt to the policy of medical waste management}

Article 11 of the measures for the management of medical wastes in medical and health institutions points out that according to the categories of medical wastes, medical wastes shall be divided into packages or containers conforming to the standards for special packages and containers of medical wastes and the provisions on warning signs; infectious wastes, pathogenic wastes, injury wastes, pharmaceutical wastes and chemical wastes shall not be collected together. A small amount of pharmaceutical waste may be mixed with infectious waste, but it shall be indicated on the label; the management of discarded narcotic, psychotropic, radioactive and toxic drugs and related wastes shall be carried out in accordance with the relevant laws, administrative regulations and relevant provisions and standards of the state.

Article 18 of the measures for the management of medical waste in medical and health institutions points out that when transporting medical waste, the transport personnel shall prevent the damage of packaging materials or containers and the loss, leakage and diffusion of medical waste, and prevent the medical waste from directly contacting the body.

Article 21 of the measures for the management of medical waste in medical and health institutions points out that the temporary storage facilities and equipment for medical waste established by medical and health institutions shall meet the following requirements: strict sealing measures, full-time (Part-time) personnel shall be set up to prevent non staff from contacting with medical waste; easy to clean and disinfect; obvious warning signs for medical waste and shall be provided warning signs of "no smoking" and "no food and drink".

\subsection{Adapt to the policy of medical waste management}

At present, the function of medical garbage can or toxic and harmful garbage can in the market is only sealed and painted with warning color. In the actual operation of medical treatment, various kinds of medical waste may be mixed and discarded, causing the risk of virus infection or gas emission. Therefore, it is necessary to have a garbage bin which can improve the safety, provide non-contact opening, disinfection and sealing functions, so that medical workers can more safely and conveniently abide by the "medical waste management measures of medical and health institutions", and maintain the people near the garbage can staff safety.

\subsection{Product functions and features}

\subsubsection{Product Features}

This product applies the functions of the household smart trash can to the medical trash can, and adds other functions according to the high risk of medical waste. The medical smart trash bin of this project is "Ultrasonic sensing contactless debris bucket based on Internet of Things technology", with strong tightness of function package; Infrared induction cap opening; Detect the concentration of air humidity, temperature, smoke and harmful gas in the drum, and disinfect and purify the air beyond the standard. Detection of overflowing degree of garbage in the bucket; the detection data will be displayed on the LCD and uploaded to the PC, and an alarm will be issued if there is a security hazard. Compared with the traditional ordinary plastic medical garbage can, this product has stronger sealing ability to prevent toxic gas leakage. More powerful functions, automatic cap opening sensor, high sensitivity achieve contactless medical waste disposal; real-time detection of medical waste data in the bucket exceeds the standard of disinfection and purification, higher safety; detecting the overflowing degree of the garbage in the bucket and alarm when the bucket is full. The detection data will be displayed on the Liquid crystal and uploaded to the PC terminal to remind the staff to timely clean up the medical waste and prevent the accumulation of medical waste from producing toxic and harmful gases. The functional design of this product is safer and more intelligent. It strictly abides by the "medical waste management measures of medical and health institutions", so it has a certain market prospect.

In order to make the function of garbage can more perfect, we consider to encrypt and protect the user data collected in the garbage can terminal platform on the basis of the original garbage can. Looking at the existing $\mathrm{R} \& \mathrm{D}$ technologies, we choose the blockchain platform with decentralized and data hard to tamper with to encrypt and protect users' privacy. The asymmetric encryption technology is used to upload the data collected by the garbage can terminal platform to the blockchain, so that the data is encrypted and saved in the distributed network.. 
After analyzing and summarizing the data through the medical trash can terminal platform, medical personnel need to store the data about medical waste to the blockchain for preservation, then take the data from blockchain as needed, and provide them for the medical supervision functional departments to conduct analyze service. In order to prevent the forgery of identity leading to leak the private data when manually uploading the data about medical waste to the blockchain, we use digital signature technology to reduce the occurrence of forgery, denial, impersonation and tampering.

The specific process of trash can data on-chain and off-chain is as follows: First, use the signer's signature private key to encrypt the data about medical waste, and when the data needs to be used, the system calls the signer's signature public key to decrypt these data and send them to the medical supervision functional departments; then, the medical supervision functional departments will collect complete data and analyze them carefully, so that they can design the optimal decisionmaking plan for the safe treatment of medical waste based on the medical trash can in order to strengthen the safety of medical care; finally, the decisions and suggestions will be given to the medical and chemical unit for implementation At the same time, re-encrypt the relevant feedback information of the deployed medical trash can and store them to the blockchain with signatures so that the trash can can be updated later based on the decrypted real feedback information.

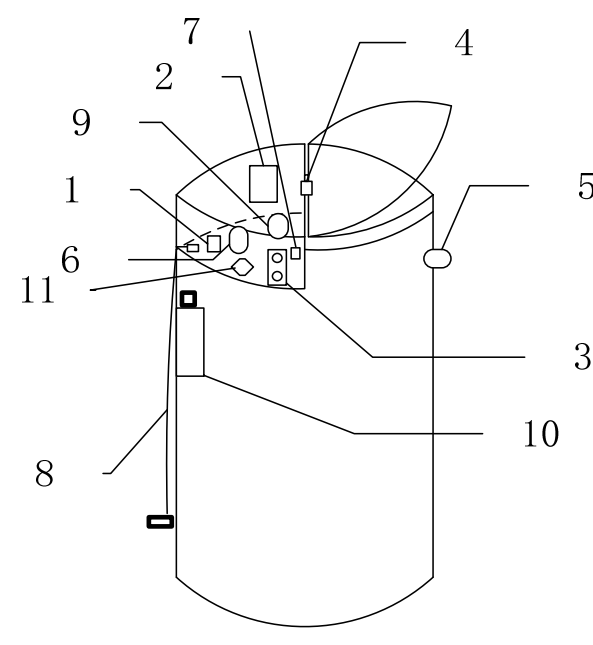

$\begin{array}{ll}\text { (1) } & \text { STM32F1 } \\ \text { (2) } & \text { OLED (0.9CIIC) } \\ \text { (3) } & \text { Ultrasonic module } \\ \text { (4) } & \text { Stepper motor+ULN2003 } \\ \text { (5) Infrared sensor } \\ \text { (6) DHT11 } \\ \text { (7) MQ-2 } \\ \text { (8) } \\ \text { (9) } \text { Buzial port line } \\ \text { (10) Motor driven spraying) } \\ \text { (11) } \text { MQ-7 }\end{array}$

Figure 2 Ultrasonic sensing of contact-free medical debris bucket based on Internet of Things technology

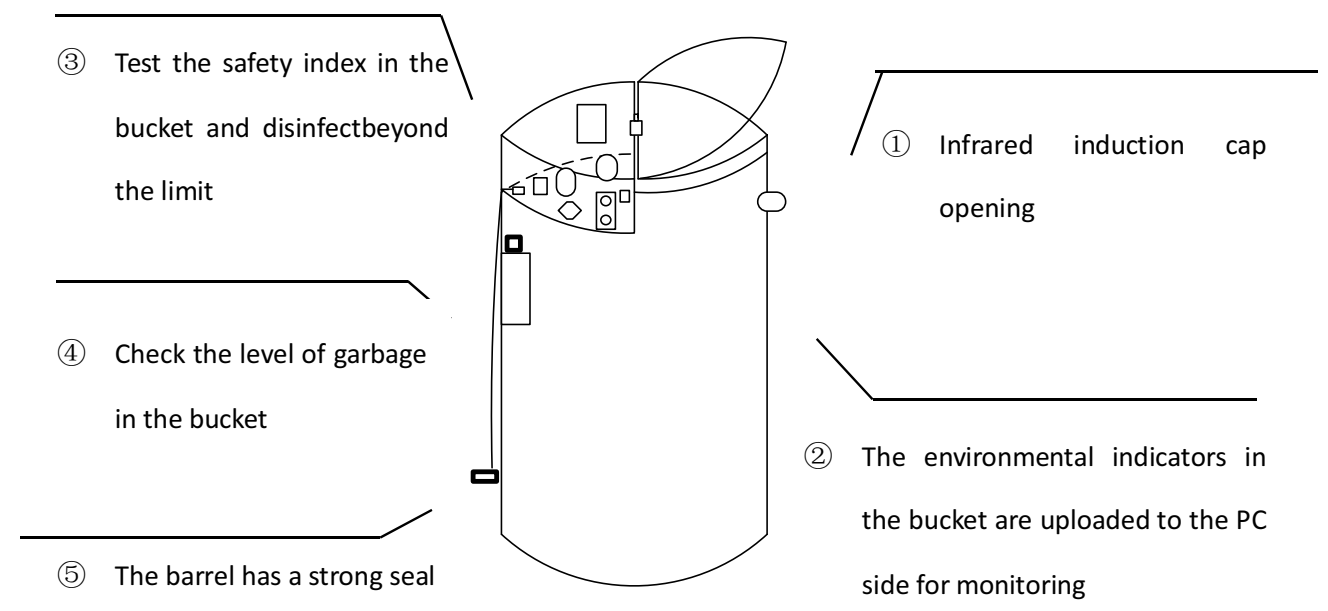

Figure 3 Function list diagram 


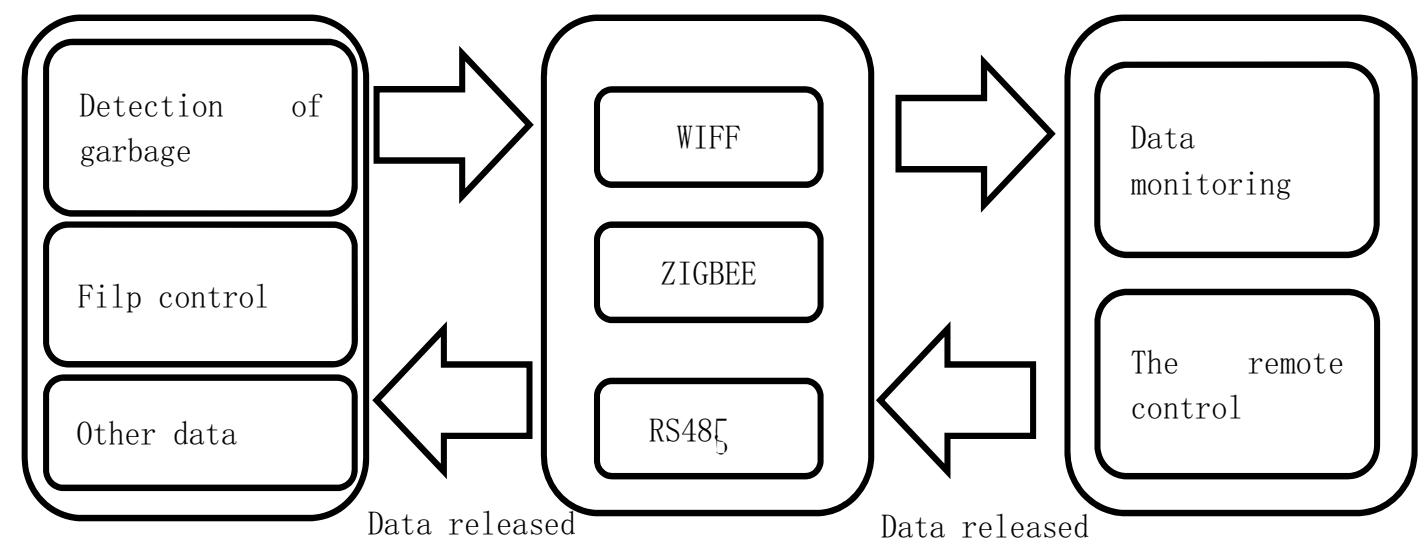

Figure 4 The flow chart

\subsubsection{Product production mode}

The matching problem of supply and demand is always around the manufacturing enterprises. According to the data of the National Bureau of statistics, the inventory of furniture industry in February 2020 is 74.06 billion yuan, and the maximum value is increasing every year ${ }^{[\mathrm{v}]}$. In order to solve the matching problem of supply and demand, we can match the supply and demand by producing corresponding products according to the customer's demand through the way that the user's demand directly puts forward to the manufacturer. As early as 2013, Alibaba proposed the concept of C2M. However, it was not until March 2020 that Taobao officially issued the $\mathrm{C} 2 \mathrm{M}$ (customer to manufacturer) strategy. But in fact, the implementation of e-commerce platforms represented by Taobao is basically F2C (factory to customer), not $\mathrm{C} 2 \mathrm{M}$. The difference between the two is that although F2C is sold directly from the manufacturer to the customer through the platform, it has no direct connection with the customer's demand. The customer can only choose and purchase what the factory produces. What's special about $\mathrm{C} 2 \mathrm{M}$ is that the customer's demand is directly connected to the factory, and the factory will produce whatever the customer needs. At present, among the enterprises that have realized $\mathrm{C} 2 \mathrm{M}$, there are more garment and textile enterprises. The reason is that clothing can be designed and produced by hand, software drawing and mechanical processing at the same time. The cost of customization is not high, so it has advantages in the field of customization $^{[\mathrm{vi}]}$. However, in addition to clothing and textile enterprises, the performance of small household appliances in the $\mathrm{C} 2 \mathrm{M}$ field is also favored by the industry, and small household appliances are also pointed out as the best way to realize the comprehensive implementation of $\mathrm{C} 2 \mathrm{M}$ in the future.

In the current medical garbage can industry, the products are relatively simple, mainly with pedal and color eye-catching plastic garbage cans and sharp tool boxes. However, in fact, the classification and treatment of medical waste are very complex, including infectious waste, pathological waste, injury waste, pharmaceutical waste and chemical waste. The treatment methods of each kind of waste are different, and different hospitals have different specific treatment methods on the basis of meeting the specified methods. Therefore, there is a demand for customization in the current medical garbage can industry. One of the reasons why the real C2M business model is difficult to be used in most manufacturing enterprises is that the R\&D cost of customized industrial products is too high, and it is only aimed at the needs of individual users. Therefore, it is difficult to make up for the cost of the production line, which makes it difficult to implement the $\mathrm{C} 2 \mathrm{M}$ mode. In medical institutions and chemical enterprises, although the treatment methods of hazardous waste are different, the required functions are similar, such as non-contact, data detection, disinfection and alarm. Therefore, if an intelligent garbage can is produced, the main functions are non-contact inductive cover opening, data detection, disinfection and alarm, and the function modules on the intelligent garbage can be replaced, increased or decreased. After a function is determined, the mass production can be carried out for subsequent users with the same demand, and the problems of $R \& D$ and production costs can be solved to a certain extent.

\subsection{Marketing channels}

\subsubsection{Preliminary pilot cooperation}

For the newly established intelligent product enterprises, they will face the problems of low market popularity and low market share. Therefore, the company needs to know whether the product meets the market consumer demand, so as to find a reasonable breakthrough in the initial marketing. The company can make full use of campus resources and government resources to get in touch with the school health Department, small chemical 
laboratories and chemical enterprises, and provide them with free experience of intelligent medical trash can, so they can break the market brand barriers. The advantages and intelligence of the garbage can have a strong persuasive power, which is a good start for the later wholesale ordering of enterprises. For further implementation of the general office of the central committee of the communist party of China, issued by The General Office of the State Council "about deepening the review of the opinions of the examination and approval system reform to encourage pharmaceutical medical equipment innovation", we should accelerate the innovation and development, medical equipment industry in producing trash cans and other related medical equipped with smart companies should seize the chance to release system of medical apparatus and instruments registrant dividends, with intelligent medical equipment innovation and development. However, as large hospitals are stricter in purchasing medical trash cans and have higher requirements on safety coefficient and intelligence, the company can promote pilot projects to large hospitals after gaining a certain popularity in small medical chemical and other places. Considering the centralized purchasing medical trash cans and other equipment and technical personnel's long-term use of habits, product technical service cooperation degree, want to fully make the staff feel smart barrels of safety and convenience, improving customer stickiness, also needs to use the free experience activities in advance, and fill out the assessment by the hospital after the probation period, as reference in the late procurement.

\subsubsection{Co-development of distributors and direct sales by manufacturers.}

The main problem faced by medical device sales is the single distribution channel, which still adheres to the traditional direct sales model of on-site promotion. For example, sales representatives of the company negotiate and promote with major hospitals or participate in bidding, sell at medical industry conferences or exhibitions, and directly publicize with target customers. Single channel leads to low market popularity, which cannot improve sales volume and brand building.

In order to solve this problem, the company should build diversified marketing channels, add first - and second-level agencies on the basis of traditional channels, and rationally use the distribution mode to expand the market share ${ }^{\text {vii] }}$. It is an effective distribution model to find powerful dealers with cooperative intention. Dealers have a strong geographical relationship, including stable human resources: relationship with the government, tax and sticky customers; The liquidity ability of the fund, which can be timely payment to the account; The normal operation of warehousing, distribution and transportation functions, which can not only save a lot of costs for the company, but also sell to major hospitals and other medical institutions through distributors. Dealers as to help the company to expand market share, improve market awareness, product benefits into the main link, saved the company the cost of business people in all regions to develop the market, the company's internal marketing head of marketing and the dealer sales professionals together, share market, industry trends, consumer behavior and so on, in order to develop more efficient product marketing mode. Due to the ownership of the dealers in different regions with selling products, and through the transfer of ownership or distributors to sell the products to retailers, to earn profit margin, therefore, company should give full consideration to the various areas of product demand, decided to different areas of the number of suppliers, and actively discuss, negotiate contract price, the product model, sales, popularizing after-sales mechanism, the marketing expenses, etc., ensure legal compliance products for sale. Through distributors to form their own brand sales channels, sign strategic cooperation contracts, establish their own brand agency chain, have stable target customers, create more sales ${ }^{[v i i]}$. However, it should also be noted that since the distributor is an independent legal person and the company signs a sales contract, both parties should agree on the ownership of end users and other issues, so as to avoid conflicts of interest after cooperation.

At the same time, the company adopts direct selling by manufacturers, establishes its own official website, displays and sells intelligent medical garbage cans. It is mainly responsible for docking with customers in bulk wholesale and directly facing end users. Direct sales can help the company obtain first-hand market information, have a better understanding of the company's product positioning, product performance and customer satisfaction, and have more advantages in the market competition. Besides, the elimination of middlemen also increases the profit greatly. If the company only sells through dealers, it may lose direct control of the market. The feedback information from dealers may be untrue, not timely, and not comprehensive, leading to the failure of the factory to make the most beneficial market decisions $^{[\mathrm{ix}]}$. Therefore, distribution + direct selling can effectively avoid the shortcomings of their respective models and bring more economic benefits to $R \& D$ companies.

\subsubsection{Adapt to the development direction of e- commerce}

With the continuous rise and development of online ecommerce industry, offline physical stores have also been impacted to a certain extent. The company should seize the opportunity to establish in-depth cooperation with e-commerce enterprises of well-known domestic brands such as Alibaba, JingDong and SuNing, and apply for medical and health license and official brand certification in advance to ensure product quality, public praise and smart patents, establish the image of credit degree, safety and intelligence, and gain customer trust. At the same time, expanding the online sales channels of smart trash can also enhance the coordination among distribution channels, achieve information sharing with dealers, and establish a customer service database. It simplifies the sales process, reduces the profit cost of 
intermediate dealers and other downstream enterprises, and effectively reduces the actual price of smart garbage bins for medical enterprises ${ }^{[\mathrm{x}]}$.

\subsection{Publicity}

The use of intelligent medical waste bins is in line with the relevant national policies on medical waste treatment, promoting the development of environmental protection, effectively realizing waste reduction, resourceization and harmlessness; truly realizing the upgrade of environmental protection, hardware and software equipment, publicity and guidance upgrade, supervision and management upgrade. The company's publicity methods mainly include personnel marketing, advertising, public relations activities. The company combines the safety and efficiency of ultrasonic sensing non-contact medical waste bucket with the social awareness of medical health to promote the development of safe and intelligent medical care. We use our distributors to promote our products and services, to make up for the lack of communication between advertisements and promotions, and to win the trust of customers. Through advertising, we establish the company's brand awareness and reputation in the market, and offer concessions to wholesale purchasers and onetime payment consumers.

Brand marketing is one of the important factors for the non-professional general retail user. The brand is the impression that exists with the customer's mind, the impression needs to be accumulated and promoted for a long time, and the brand image should also meet the consumer's needs. For example, Cadillac cars have been producing special cars for the President of the United States since 1993, so the impression in the minds of consumers is that of safety, ruggedness and luxury, which is what car consumers want when they buy a $\mathrm{car}^{[\mathrm{xi}]}$. In the brand of trash cans, especially smart trash cans, the demand that consumers value when buying is safety and hygiene, and the smart trash cans that can be used in professional places such as medical institutions and chemical companies must have very high standards of safety and hygiene, so as to be able to due to create a safe and healthy brand image. On this basis, increase the promotion and marketing of the brand, and launch the corresponding simple version of the smart trash cans, to provide ordinary consumers who use smart trash cans in non-specialized settings.

\subsection{Comparison and innovation}

China's trash can industry is currently in its infancy, and resource integration and profitability are in urgent need of breakthroughs. The current business model of China's trash can industry is partly characterized by "ecommerce of trash cans", using the Internet as a supplementary means of marketing channels; and providing low prices the products can only solve the shallow industry pain points. The Internet and the integration of upstream and downstream resources in the trash can industry provide consumers with money-saving, trouble-saving, and labor-saving services in the form of "low-price packages + service commitments + process monitoring". In the future, the profitability of the trash can industry is mainly based on its ability to integrate resources from all parties and creative transaction flow.

\subsubsection{Traditional business model}

At present, the medical trash cans on the market are mainly produced by plastic companies or environmental protection companies. Most of the products are yellow, which is more eye-catching than ordinary plastic trash cans, and the barrels carry environmental protection signs. However, the existing medical trash cans have the same functions as ordinary plastic trash cans. They can only be used to load garbage. They have no other functions. They cannot disinfect and treat toxic medical waste, and lack safety. Due to the large demand for general medical trash bins and their low prices, the sales model is based on direct sales by manufacturers such as environmental protection equipment companies or plastic manufacturers. With the rapid development of the e-commerce industry in recent years, e-commerce cooperation has gradually increased.

\subsubsection{Innovative business model}

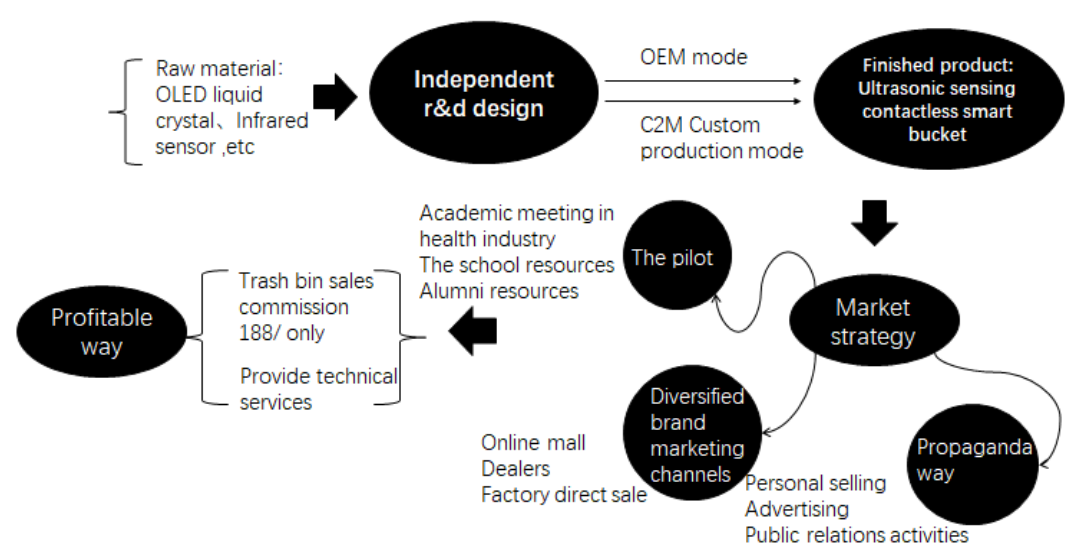

Figure 5 Business model icon 
This business model is the company's first research and development product. The original ordinary plastic medical trash can is researched and developed, and smart functions are developed. The smart trash can and the medical trash can are combined to improve safety; with the "Internet of Things + Therapy Trash Can" model, Connect the trash cans, monitor and manage the medical trash cans through the PC terminal, and promptly remind the staff to clean up.

The production model adopts "OEM products", signs agreements with suppliers, produces products developed by the company, and uses 3D printing for mass production during the production process. Before the official sale, the use of campus resources and government resources to provide a free experience of smart medical trash cans, pilot launch, open market breakthroughs, and verify the effectiveness of the product. In order to rapidly expand the market scale and break the traditional strategy of winning at low prices with trash cans, the company should build diversified marketing channels, cooperate with distributors at the beginning of the period, and use the cooperative relationship between distributors, hospitals and related chemical companies to put products on the market. After the product has a certain degree of maturity and popularity, the official website of the product is opened, and customers can buy directly on the website, and can buy at a preferential price through direct sales. At the same time, it cooperates with various well-known ecommerce platforms. The user groups of well-known ecommerce platforms are larger, and the audience of the products that cooperate with them is wider, which improves the product exposure rate and enables the products to truly stand in the market. Throughout the entire marketing process, we will continue to carry out personnel promotion, advertising, public relations activities and other publicity methods, and focus on brand marketing, establish product safety and hygiene brand image, increase user trust, and enhance user stickiness.

\section{Conclusion}

It is estimated that the medical market for medical trash cans is about 9.75 billion yuan ${ }^{\text {[xii] }}$. The market scale is large; the "Medical Waste Management Measures for Medical and Health Institutions" clearly stipulates that medical waste needs to be classified, medical waste is strictly prohibited from contacting the body, and temporary storage facilities for medical waste must be tightly sealed, cleaned and disinfected; there is a gap in the market for smart medical trash cans. Through analysis, the following conclusions can be summarized. The medical trash can market requires intelligent products, which integrates contactless opening, closing, cleaning, and disinfection. At the same time, it requires real-time monitoring and management of the Internet of Things technology to process medical waste in a timely manner. In order to make the smart trash can quickly popularized, it is imperative to update the business model. Production is through OEM factory foundry, 3D printing mass production, $\mathrm{C} 2 \mathrm{M}$ production mode to achieve customization, product trials before sales, product quality verification, and later "Direct sales + Distributors + E-commerce" multi-channel sales, and use personnel sales, advertising, public relations activities and other publicity methods to create brand effects and promote products quickly. This article aims to provide innovative products and business model ideas for the medical trash can industry and open up new markets for medical trash.

\section{Acknowledgment}

This project is funded by the construction of the "2020 Shanghai University Student Innovation and Entrepreneurship Training Program Model School”.

\section{Reference}

1. Hu Hanmin. Discussion on the sales Model of medical Devices [J]. Marketing, 2019(25):155+157.

2. Ao Xiaobo, Xie Zhihua, Yang Chao. Production Optimization and process Reengineering of enterprises under F2C mode [J].Finance and Accounting, 2016(13):27-28.

3. Dong Xiaozhi.C2M Model Analysis of Internet Direct Selling [J]. Journal of Chongqing University of Science and Technology (Social Science edition), 2016(12):51-52.

4. Wei Hongmei. Lin Hua medical (835637) in depth report: domestic indwelling needle consumables lead, industry concentration increase [R]. Dongguan securities, 2020

5. Zhu Yun. Can C2M solve business problems? [N] People's Posts and telecommunications, 2020

6. He Liping, Wang Jinlong. Research on the competitive advantage of the Internet plus business mode -- Based on the perspective of enterprise dynamic capability [J]. Journal of Suihua University, 2020,40 (05): 18-21.

7. Wang Danhong. Analysis and Research on marketing Mix Strategy of Medical Devices [J]. School of Business, Renmin University of China.

8. Sun Junke. On the marketing strategy of medical device distributors.

9. Li Xiguang. A Comparative Study on distribution and Direct selling Model of plastic raw materials sales -- A case study of domestic copolymeraldehyde.

10. Wan Weiliang, Zhang Nianping. Research on marketing Channel Innovation of Medical device enterprises in China under the background of great health industry development.

11. Zhi Qin. The Special car of the President of the United States [J]. 2017(06):52-53.

12. Wei Hongmei. Lin Hua medical (835637) in depth report: domestic indwelling needle consumables 
lead, industry concentration increase [R]. Dongguan securities, 2020 